\title{
Neck Swelling Caused by Achalasia
}

\author{
Yoichi Hoshino $^{1}$, Toshiro Ikeya ${ }^{2}$ and Moriya Machida ${ }^{1}$
}

Key words: achalasia, neck swelling, airway obstruction

(Intern Med 59: 745, 2020)

(DOI: 10.2169/internalmedicine.3674-19)
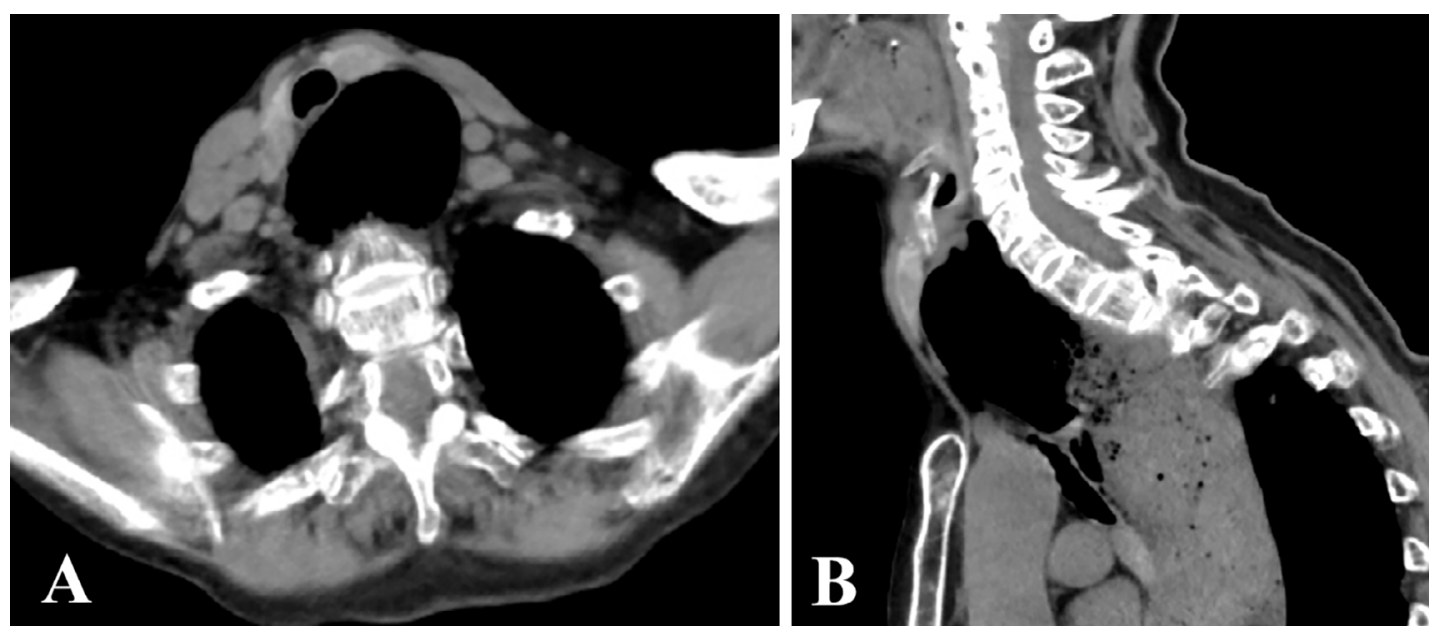

Picture.

Up to $37 \%$ of patients with airway obstruction caused by achalasia present with neck swelling (1). However, there are few reports on the computed tomography (CT) findings of neck swelling caused by achalasia. We herein report a remarkable case of neck swelling caused by achalasia. An 88year-old woman presented with acute-onset dyspnea and stridor after meals. She had been diagnosed with achalasia eight years earlier. She had been hospitalized with vertebral compression fracture a month earlier. Her physical findings were as follows: blood pressure, $180 / 110 \mathrm{mmHg}$; pulse rate, 120/min; respiratory rate, 30/min; percutaneous arterial oxygen saturation, $70 \%$; massive neck swelling and peripheral cyanosis. CT revealed tracheal compression between the dilated esophagus and sternum. The dilated esophagus pushed the trachea posteriorly and induced swelling in the neck (Picture). The symptoms improved with supplemental oxy- gen administration and esophageal decompression. There were no further symptoms after endoscopic balloon dilatation.

The authors state that they have no Conflict of Interest (COI).

\section{Reference}

1. Hatakeyama J, Takei T, Ito T, Takemoto M. Airway obstruction in a patient with achalasia: a case report and a review of the literature. Nihon Kyukyu Igakukai Zasshi 21: 377-382, 2010 (in Japanese, Abstract in English).

The Internal Medicine is an Open Access journal distributed under the Creative Commons Attribution-NonCommercial-NoDerivatives 4.0 International License. To view the details of this license, please visit (https://creativecommons.org/licenses/ by-nc-nd/4.0/).

\footnotetext{
${ }^{1}$ Department of Internal Medicine, Keiaido Hospital, Japan and ${ }^{2}$ Department of Surgery, Keiaido Hospital, Japan Received: July 18, 2019; Accepted: September 30, 2019; Advance Publication by J-STAGE: November 8, 2019 Correspondence to Dr. Yoichi Hoshino, fwgi9866@nifty.com
}

(C) 2020 The Japanese Society of Internal Medicine. Intern Med 59: 745, 2020 